\title{
Structural and Thermo-Mechanical Study of Aluminum Coated Polyethylene Terphthalate (PET) Film
}

\author{
Sandhya Gupta, Kananbala Sharma \\ Semiconductor and Polymer Science Laboratory, Department of Physics \\ University of Rajasthan Jaipur, India \\ 1982sanman@gmail.com
}

\begin{abstract}
Commercially available polyethylene terephthalate (PET) film of thickness of 20 um has been used as flexible substrate and aluminum has been coated on PET film using vacuum thermal evaporation method. The structural characterization of Al-PET film has been done using X-ray diffraction (XRD) pattern and Fourier transform infrared (FTIR) spectroscopy. Mechanical study of Al-PET film has been carried out using Dynamic Mechanical Analyzer (DMA). The glass transition temperature $\left(T_{g}\right)$ of Al-PET film is found to be $112.3^{\circ} \mathrm{C}$ whereas $T_{g}$ of commercial PET film is $89.7^{\circ} \mathrm{C}$. The result of stress-strain behavior of polymer films for a wide range of temperatures is useful for engineering applications therefore in the present work an effort has been made to see the effect of wide range of temperatures on metalized polymer. The stress-strain curves of Al-PET film at room and elevated temperatures explain the mechanical response of this film under the applied load.
\end{abstract}

\section{INTRODUCTION}

Due to high mechanical strength, toughness and durability, biaxially oriented and heat stabilized PET films are widely used in variety of industrial applications. These include the insulation for electric motors, capacitors, wires and cables as well as the base material for audio, video and computer tapes. Most of these applications require a metallization of the polymer film. This is particularly true for thin films used as dielectrics in capacitors [1,2], substrate for flexible organic light emitting devices (OLEDs) [3], flexible solar cells [4], in fabrication of reflectors [5-7], corrosion protective films [8] and base films for the new generation of magnetic recording media $[9,10]$. Substrate materials are essential and prerequisite for meeting cost, performance, reliability and manufacturing goals for flexible displays. The flexible OLEDs made on indium-tin-oxide (ITO)-coated PET substrate have been tested under different mechanical stresses and no significant deterioration in the device performance has been observed when they are flexed at various bending radii [11]. These flexible OLEDs have very short lifetimes because plastics exhibit low resistance to moisture and oxygen. It is known that most metals possess lower gas permeability than plastics by $6-8$ orders of magnitude [12]. Therefore, a several micrometer thick metal layer can serve as a highly effective barrier to minimize the permeation of oxygen and moisture. For example aluminum coated PET foil has good mechanical flexibility and superior barrier properties. Packaging films are mostly metalized with aluminum in a thermal evaporation process. The suitability of PET films for vacuum metallization is related to its moisture retention, which is below $0.5 \%$ at $25{ }^{\circ} \mathrm{C}$ and a $50 \%$ relative humidity [13]. For the use of metalized polymer films in flexible devices, the adhesion of metal layer to polymer base film should be good and it is proved by many researchers that most of the metals show excellent adhesion with polymers [14-16]. The effect of temperature on stress-strain behavior of PET has been observed by Denardin et al. [17]. The result of stress-strain behavior of polymer films for a wide range of temperatures is useful for engineering applications [18] therefore in the present work an effort has been made to see the effect of wide range of temperatures on metalized polymer. The change in mechanical stability, stiffness and elasticity of metalized polymer films with temperature is also important issue of study for the application point of view. A lot of work has been done on the composition, microstructure and morphology of the evaporated metal layers and their adhesion to the polymer base films but very few studies so far have been done on the mechanical properties of metalized PET films [19, 20].

In this present study metalized PET film (Al-PET) has been formed by vacuum evaporation of aluminum (Al) on PET substrate in form of a film. Scanning electron microscopy (SEM), has been 
used to determine surface morphology of the PET film and Al-PET films. The FTIR spectra of these films have also be taken to confirm the bonding of metal ions with polymer matrix. Mechanical properties such as Young's modulus $(\mathrm{Y})$, storage modulus $\left(\mathrm{E}^{\prime}\right)$, glass transition temperature $\left(\mathrm{T}_{\mathrm{g}}\right)$, tensile strength $(\sigma)$, yield strength $\left(\sigma_{y}\right)$ of PET and metalized PET films have been calculated from temperature scan and stress-strain scan at room temperature using DMA. Besides this an effort has also been made to study the variation of yield strength with temperature using the stress-strain curves obtained at different temperatures with constant strain rate of these so prepared samples.

\section{EXPERIMENTAL}

Commercially available PET film (from Good Fellow Cambridge Limited, England) of dimension $7.5 \times 7.5 \mathrm{~cm}$ and thickness $20 \mu \mathrm{m}$ has been metalized with aluminum (aluminum single crystal disc, from Aldrich Chemical) by vacuum thermal evaporation method [21, 22] in a residual pressure 10-5Torr to form Al-PET film. In this evaporation technique molybdenum boat has been used as source. The temperature of metal (Al) kept in the boat has been increased by flowing the current through it. The evaporation temperature of metals has been kept around $100^{\circ} \mathrm{C}$. The thickness of metal coating on PET substrate as measured from Quartz thickness monitor (Model CTM 200) has been found to be $0.2 \mu \mathrm{m}$. The size of metal particles has been calculated by X-ray analyses performed with a Philips X'pert X-ray diffractometer using copper target $(\mathrm{Cu}, \mathrm{K} \alpha)$ at a scanning rate of $3^{\circ}$ per minute between 10 to $60^{\circ}$. Scanning electron microscopy (SEM) images of PET and Al-PET films have been obtained by FEI Quanta $200 \mathrm{~F}$ equipment, where only PET sample was gold-sputtered prior to measurements. The thickness of Al coating of SEM preparation was found to be $40 \mathrm{~nm}$. The FTIR absorption spectra were recorded in the frequency region 4000-400 cm-1, using model IR Affinity-1, Shimadzu spectrophotometer. The accuracy of the measurement is $\pm 4 \mathrm{~cm}^{-1}$ in 4000 to $2000 \mathrm{~cm}-1$ region and $\pm 2 \mathrm{~cm}^{-1}$ in 2000 to $400 \mathrm{~cm}-1$ region. The mechanical properties of these metallized films have been studied by DMA with model Tritac 2000. DMA is a sensitive technique that characterizes the mechanical response of materials by monitoring property change with respect to the temperature and frequency of applied sinusoidal stress [23-25], which has been produced by forced oscillations in DMA. Samples to be used in DMA have been cut length wise into the size of $8 \mathrm{~mm}$ in length and 4-5 $\mathrm{mm}$ in width, to confirm the dimensional limits for tension clamp fixtures. The average thickness for each sample was based on separate measurements, taken at the two ends. After mounting the sample in tension clamp, the furnace was sealed off, scanned over a temperature range from room temperature to $180{ }^{\circ} \mathrm{C}$. The heating ramp rate was $2{ }^{\circ} \mathrm{C} \min ^{-1}$ for all temperature scan tests. Frequency of oscillations was fixed at $1 \mathrm{~Hz}$ and strain amplitude $0.01 \mathrm{~mm}$ within the linear viscoelastic region. The storage modulus E', loss modulus E" and mechanical loss factor (Tan $\delta$ ) have been determined during the test as a function of increasing temperature. The stress-strain scans for PET and Al-PET films are taken at room temperature and also at elevated temperatures $\left(60{ }^{\circ} \mathrm{C}-180\right.$ $\left.{ }^{\circ} \mathrm{C}\right)$ with constant strain rate of $2 \mathrm{~min}-1$.

\section{RESUlTS AND DISCUSSION}

\subsection{Material Characterization}

\subsubsection{X-ray analysis}

Fig. 1 shows the X-ray diffraction patterns of pure PET and Al-PET films. The presence of the intense and broader peak in the range of $2 \theta$ from 20 to $30^{\circ}$ in Fig. 1 can be assigned to the semi crystalline structure of PET polymer [26, 27]. This semi-crystalline structure of PET seems to be related to extrusion process (lateral stretching) employed in the production of PET films. When lateral stretching process is not employed, amorphous PET film is produced [14]. The presence of aluminum metal is observed in XRD patterns of Al-PET film where the peaks at $2 \theta=38.37^{\circ}$ and $44.78^{\circ}$ is assigned to (111) and (200) planes of the aluminum crystalline structure. The grain size of the crystallites (D) has been estimated using the following relation [28]:

$\mathrm{D}=\mathrm{k} \lambda /(\beta \cos \theta)$

where $\mathrm{k}$ is shape factor $(\approx 1), \lambda$ is the wavelength of $\mathrm{X}$-ray used, $\theta$ is Bragg's angle and $\beta$ is the FWHM of the peak. The grain size of aluminum particle is around of $25 \mathrm{~nm}$. 


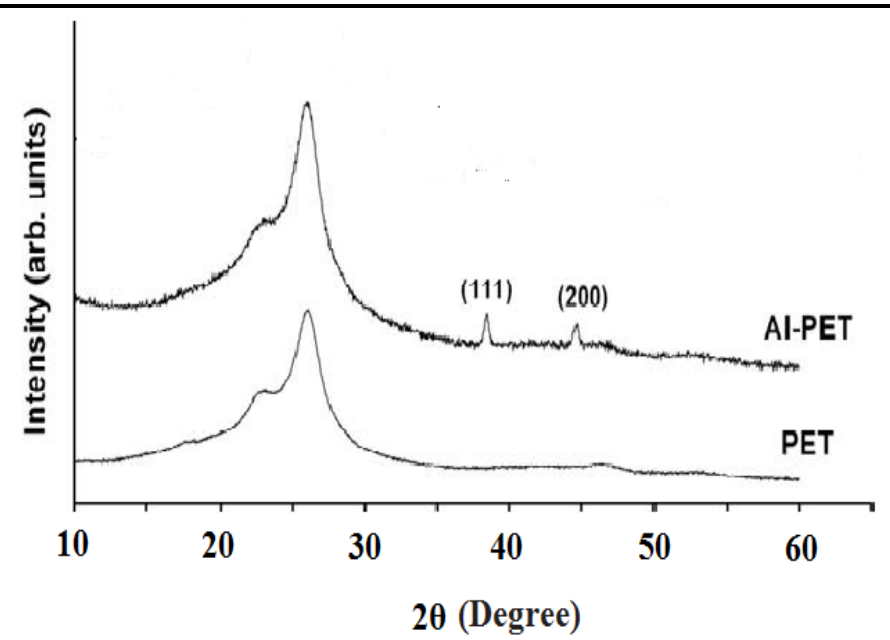

Fig1. $X$-ray diffraction pattern of PET and Al-PET films at room temperature

\subsubsection{SEM analysis}

The SEM images of PET and aluminium coated PET films have been shown in Fig. 2(a) and (b). This analysis was performed in order to verify the presence of the metal particles on PET substrate. The metallized PET film presents a continuous globular structure on surface while the PET film presents a planner sheet structure.

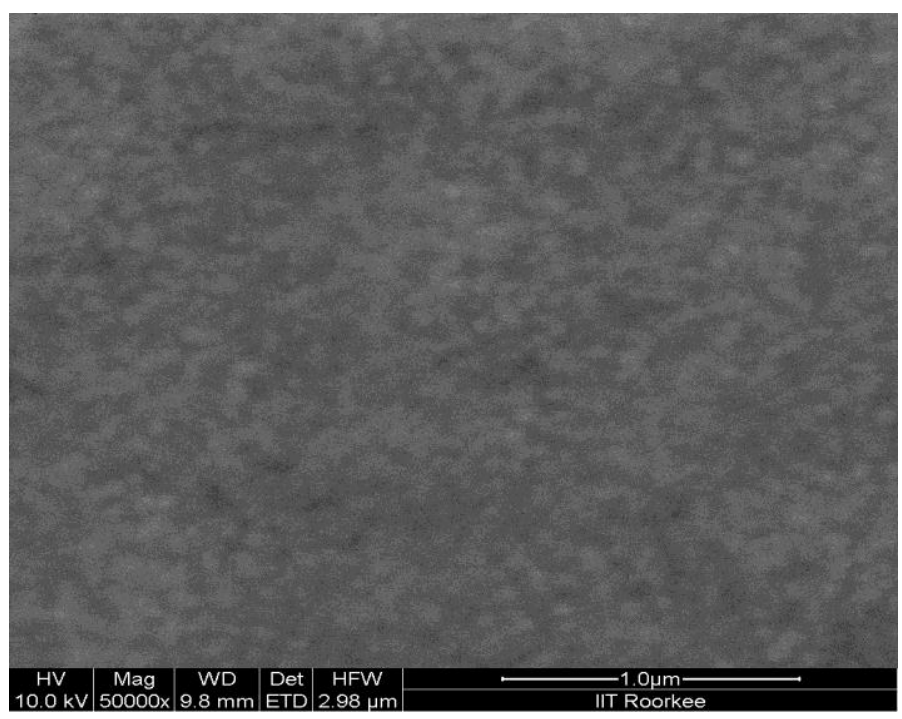

Fig2. (a) SEM image of PET film.

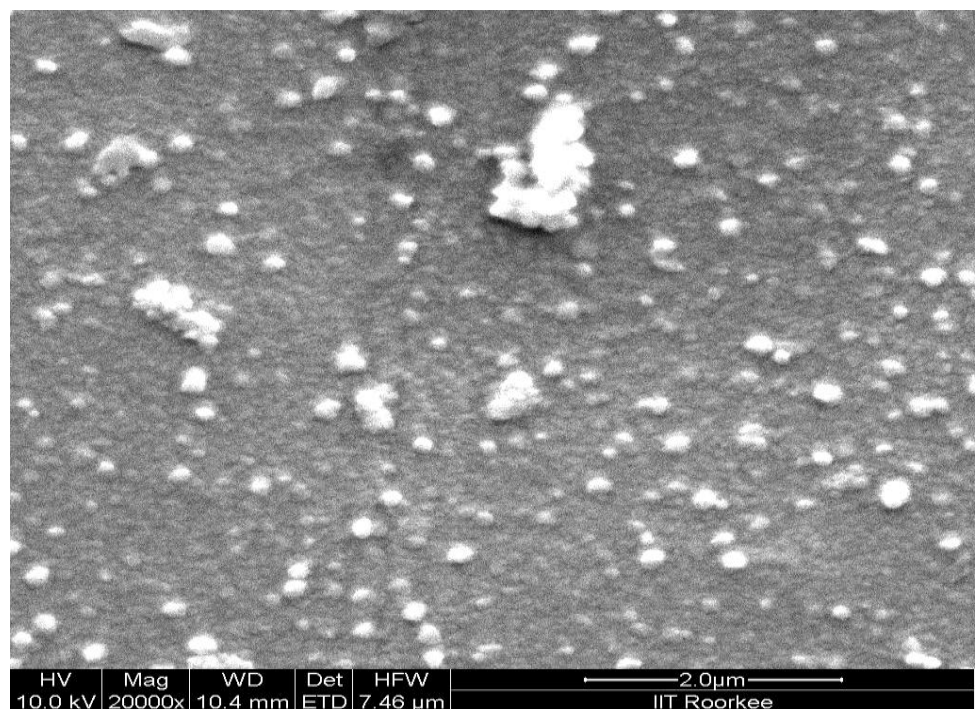

Fig2. (a) SEM image of PET film. 


\subsection{FTIR Measurements}

The FTIR spectra of PET and Al-PET samples in absorption mode are shown in Fig. 3. On comparing the FTIR spectra of PET film to metalized PET films, several new peaks which indicated chemical interaction between PET and metal (Al) have been observed. A sharp and low intensity band at 640 $\mathrm{cm}^{-1}$ in FTIR spectra of metalized PET films is attributed to Al-O stretching [29]. A sharp band around $960 \mathrm{~cm}^{-1}$ could be assigned to longitudinal stretching vibrations of $\mathrm{Al}-\mathrm{O}$ [30]. This metal bonding confirms that metal ions have been attached to the polymer chain of PET, hence altering its mechanical behaviour.

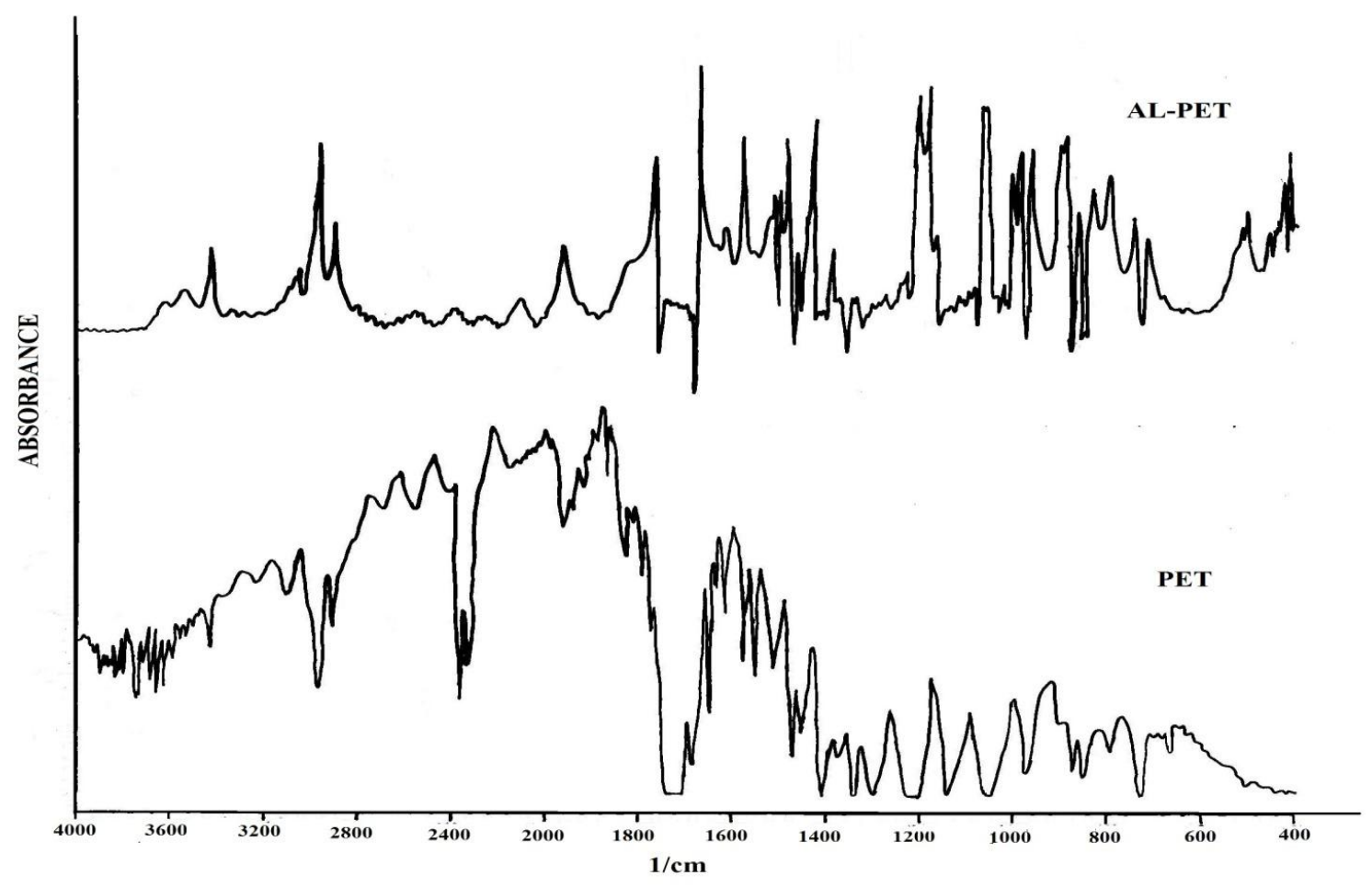

Fig3. FTIR spectra of PET and Al-PET films.

\subsection{Mechanical Properties}

\subsubsection{Storage modulus and mechanical loss factor}

Variation in storage modulus with temperature for PET and Al-PET films are shown in Fig. 4. From this figure it is observed that the storage modulus E' decreases with increasing temperature due to the softening of these films. The value of storage modulus for PET decreases from $7.64 \times 108$ to $0.934 \times 108 \mathrm{~Pa}$ as temperature increases from room temperature to $180{ }^{\circ} \mathrm{C}$ whereas the value of storage modulus for Al-PET decreases from $1.127 \times 109$ to $0.256 \times 109 \mathrm{~Pa}$ within the same temperature range. It is found that the value of storage modulus increases after metal coating on PET sheet. The percentage rise in storage modulus with respect to PET film is found to be $47.5 \%$ for Al-PET. The ions of metal have been attached to the polymer chain of PET through local resonance, which results into more compact structure and therefore, according to Crankshaft model [24], free volume decreases, which restricts the possibility of free motion of main chain in various directions. Consequently coating of metal (Al) film increases stiffness of PET sheet. Variation in mechanical loss factor (Tan $\delta$ ) with temperature for PET and Al-PET films is shown in Fig. 5. This figure shows that the value of Tan $\delta$ initially increases with temperature because of increase in loss modulus ( $\left.\mathrm{E}^{\prime \prime}\right)$ of material. As the material undergoes softening at higher temperature the heat dissipates into the material thus decreasing the elastic response, which increases the value of Tan $\delta$ up to maximum. After that the glassy phase starts to disappear and rubbery phase appears therefore the Tan $\delta$ radically decreases. Temperature corresponding to peak of Tan $\delta$ is known as glass transition temperature (Tg). It is observed that Tg of PET film is $89.7^{\circ} \mathrm{C}$ whereas Tg of Al-PET film is found to be $112.3{ }^{\circ} \mathrm{C}$. Thus an increase in the value of $\mathrm{Tg}$ has been observed after metallization of PET films. Metal (Al) coating on PET substrate film increases the stiffness of film. Metallized PET film (Al-PET) take more heat to transform from semi-crystalline phase to rubbery phase and glass transition temperature (Tg) shifts 
towards the higher temperature. The percentage rise in glass transition temperature with respect to PET film is found to be $25.2 \%$ for Al-PET. Tg is the transition at which the material moves from solid to rubbery state. This requires the straightening of the polymer chains.

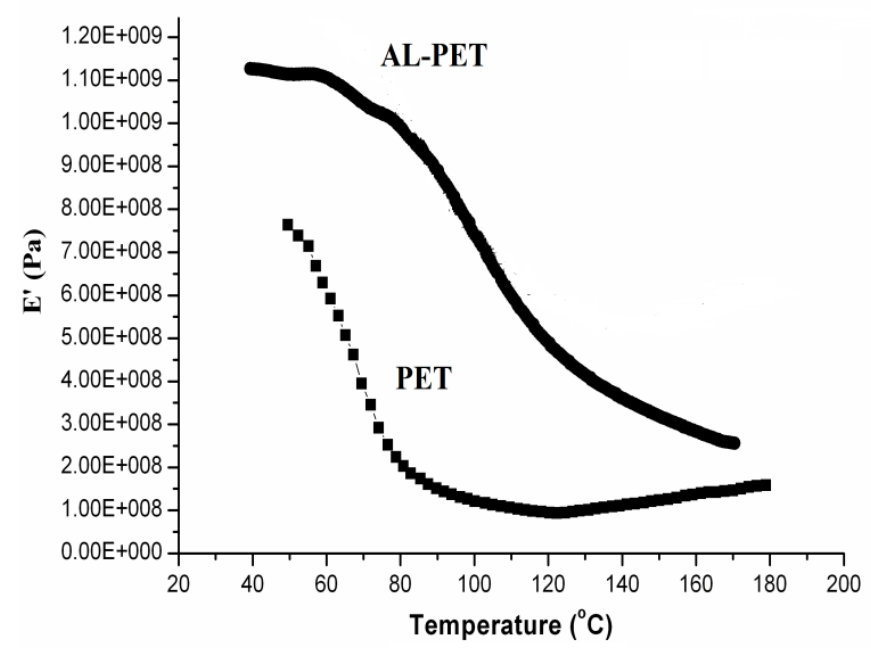

Fig4. Variation of storage modulus with temperature for PET and Al-PET films

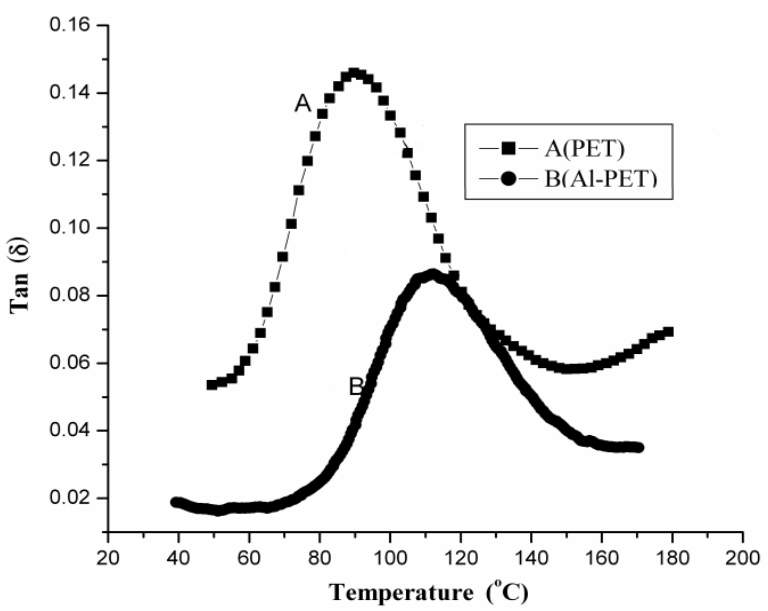

Fig5. Variation of Tan $\delta$ with temperature for PET and Al-PET films.

\subsection{Stress-Strain Test at Room Temperature}

The stress-strain behaviour of PET and Al-PET films at room temperature is shown in Fig. 6. This figure shows two characteristic regions and one phase transition for each film. The first region is characterised by an initial linear increase. The second one is characterised by the increase in the strain with a very slow increase of the stress, which is specific for plastic deformation. In this region, the specimen exhibits "irreversible" plastic deformations with increasing strain. The stress in the plastic deformation region varies very little with the strain and is often lower than the yield strength. The transition is indicated as the yield point that corresponds to the onset of plastic deformation events in polymer. The slope of initial linear region of stress-strain curve gives the value of stiffness or Young's modulus of the polymer. It is determined from the stress-strain curve that the values of Young's modulus (Y) for PET and Al-PET films at room temperature are 2.016×109 $\mathrm{Pa}$ and $2.401 \times 109 \mathrm{~Pa}$. These data also indicate that the stiffness of PET increases after metallization, which is useful property from application point of view. The tensile strength of a polymer is usually defined as the maximum stress reached during the stress-strain test or the stress when the sample breaks. The value of tensile strength $(\sigma)$ for PET and Al-PET films at room temperature is $50.45 \mathrm{MPa}$ and $67.36 \mathrm{MPa}$ whereas the yield strength $(\sigma \mathrm{y})$, which is the point where deviation from linearity occurs in the stressstrain curve, for PET and Al-PET films at room temperature is $29.69 \mathrm{MPa}$ and $52.96 \mathrm{MPa}$. The values of Young's modulus and tensile strength show percentage rise by $19 \%$ and $33.5 \%$ for Al-PET film with respect to PET film at room temperature. These results indicate that mechanical strength of PET also increases after metallization. 


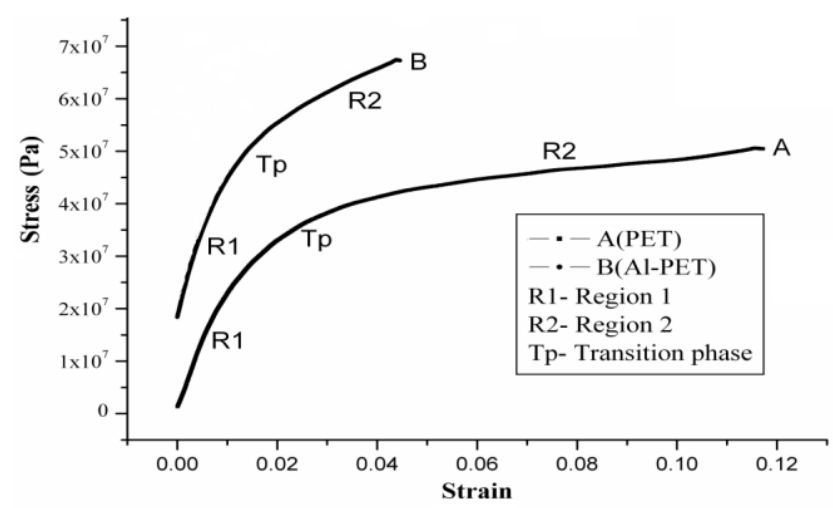

Fig6. Stress-strain behaviour of PET and Al-PET films at room temperature

\subsection{Effect of Temperature on Stress-Strain Behaviour}

As a function of test temperature stress-strain curves for PET and Al-PET films change progressively as shown in Figs. 7-8. As the temperature increases, the tensile strength and Young's modulus decrease. This qualitative behaviour is observed over the temperature range from room temperature to $180{ }^{\circ} \mathrm{C}$. Variation of the values of yield strength with temperature for PET and Al-PET is shown in Fig. 9. It has been observed from this figure that yield strength of these samples decrease almost linearly with increasing temperature up to a certain temperature beyond which it shows a slightly increasing trend. Yield strength decreases with increasing temperature. This behaviour indicates that as temperature increases the movement of the chains becomes easier and consequently, the resistance to deformation is smaller. Hence the metallized PET films showed higher resistance to deformation than that of commercial PET film.

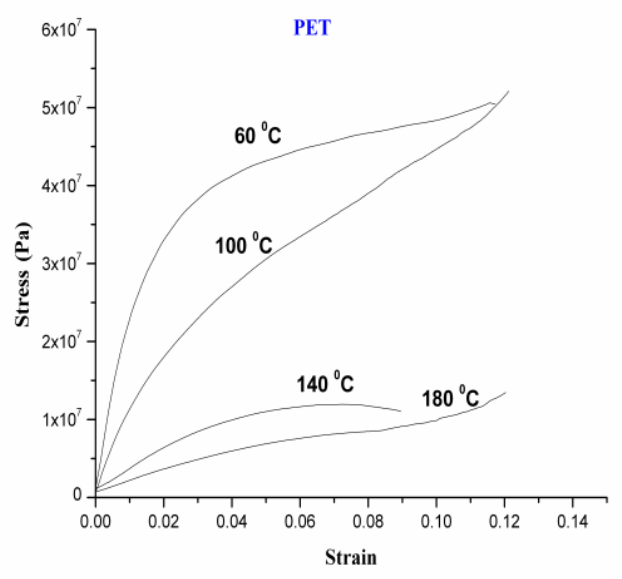

Fig7. The stress-strain curves of PET film at different temperatures

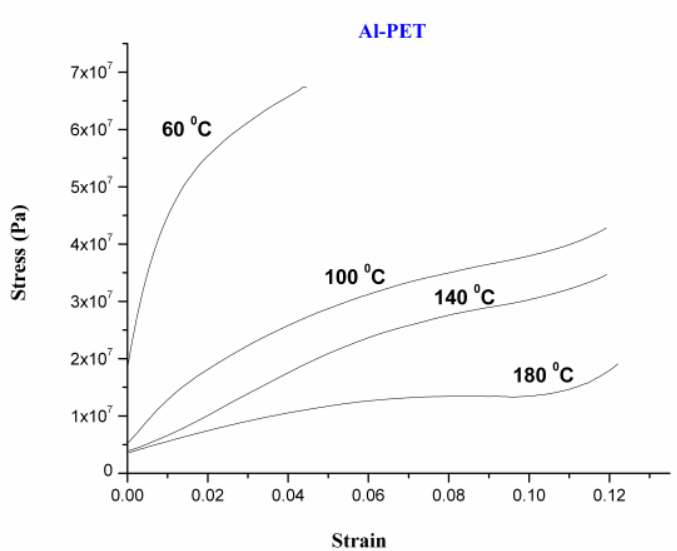

Fig8. The stress-strain curves of Al-PET film at different temperatures. 


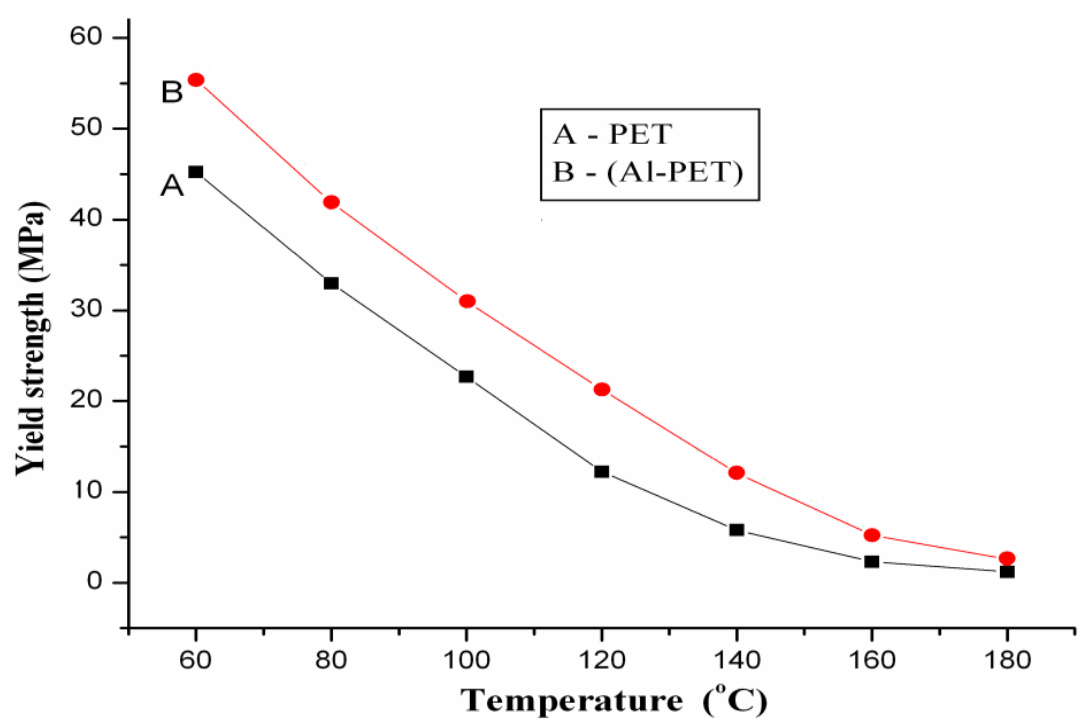

Fig9. Variation of yield strength with temperature for PET and Al-PET films.

\section{Conclusion}

Metallic coating of $\mathrm{Al}$ has been deposited on commercial PET film using vacuum thermal evaporation method. On the base of FTIR, SEM and X-ray analyses it is concluded that on increasing temperature, metal ions diffuse in polymer matrix and attach to the polymer chain of PET, which results into more compact structure. An increase in the values of storage modulus ( $\left.\mathrm{E}^{\prime}\right)$, glass transition temperature $(\mathrm{Tg})$ and tensile strength $(\sigma)$ of PET after metallization as determined using DMA indicates that the stiffness, stability and strength of PET film increase when coated with Al. The yield strength versus temperature curves for PET and Al-PET suggest that the metallized PET films show higher resistance to deformation than that of commercial PET film. So it can be concluded that on applying force, less deformation occurs in metallized PET films in comparison to commercial PET film. This property of metallized PET is advantageous for the use of these films as a substrate in flexible device fabrication such as OLED, solar cell, magnetic tape etc.

\section{ACKNOWLEDGMENTS}

Authors are thankful to Ms. Deepika Chaudhary, Ms. Manasvi Dixit, Mr. Kuldeep S. Rathore, Mr. Mahesh Baboo, and Mr. Vishal Mathur for their help in various ways during the course of this work.

\section{REFERENCES}

[1] C.W. Reed, S.W. Cichanowski, IEEE Trans. Dielectr. Electr. Insul. 1 (1994) 904.

[2] M.G. Kong, Y.P. Lee, IEEE Trans. Dielectr. Electr. Insul. 11 (2004) 1007.

[3] Y. Li, L.W. Tan, X.T. Hao, K.S. Ong, F. Zhu, Appl. Phys. Lett. 86 (2005) 153508.

[4] A. Romeo, G. Khrypunov, F. Kurdesau, M. Arnold, D.L. Batzner, H. Zogg, A.N. Tiwari, Sol. Energy Mater. Sol. cells 90 (2006) 3407.

[5] R.E. Southward, C.J. Dean, J.L. Scott, S.T. Broadwater, D.W. Thompson, Mater. Res. Soc. Symp. Proc. 703 (2002) 421.

[6] John Harrison, Report: Investigation of reflective materials for the solar cooker, Florida Solar Energy Centre, 2001.

[7] C. Kennedy, G. Jorgensen, State-of-the-Art Low-Cost Solar Reflector Materials, $8^{\text {th }}$ International Vacuum Web Coating Conference, Nevada, 1994.

[8] R.M. Bikchentaev, K.V. Zvezdinskii, V.V. Pugach, N.P. Umanchik, I.B. Kabal'nikova, Chem. Petrol. Eng. 26 (1990) 319.

[9] X. Li, B. Bhushan, IEEE Trans. Magn. 37 (2001) 1616.

[10] B. Bhushan, Mechanics and Reliability of Flexible Magnetic Media, 2nd ed., Springer, New York, 2000, p. 76.

[11] R. Paetzold, K. Henseler, S. Roeger, G. Weittmann, A. Winnacker, Appl. Phys. Lett. 82 (2003) 3342. 
[12] R.R. Tummala, E.J. Rymaszewski, Microelectronics Packaging Handbook, Van Nostrand Reinhold, New York, 1989 Chap. 10.

[13] C.J. Heffelfinger, K.L. Knox, in: O.J. Sweeting (Ed.), The Science and Technology of Polymer Films, vol. II, Wiley, New York, 1971, p. 587.

[14] P. Ziegler, M.F. Vallen, H. Haidara, J. Schultz, J. Mater. Sci. 32 (1997) 1809.

[15] J.D. Rancourt, J.B. Hollenhead, L.T. Taylor, J. Adhes. 40 (1993) 267.

[16] P. Phuka, P. Bertrand, Y. De Puydt, Thin Solid Films 200 (1991) 263.

[17] E.L.G. Denardin, S. Tokumoto, D. Samios, Rheol. Acta 45 (2005) 142.

[18] J. Richeton, S. Ahzi, K.S. Vecchio, F.C. Jiang, R.R. Adharapurapu, Int. J. Solids Struct. 43 (2006) 2318.

[19] B. Cyziute, S. Tamulevicius, P. Goudeau, M. Andrulevicius, A. Guobiene, Surf. Coat. Technol. 200 (2006) 6590.

[20] L. Murray, P. McCarry, J. Plast. Film Sheeting 19 (2003) 55.

[21] O.S. Heaven, Pert. Progr. Phys. 23 (1960) 1.

[22] A. Vasicek, Optics of Thin Films, North Holland Publishing Company, Amsterdan, 1960.

[23] S. Gupta, V. Shaktawat, K. Sharma, N.S. Saxena, T.P. Sharma, AIP Conf. Proc. 1004 (2008) 328.

[24] M. Dixit, V. Shaktawat, K. Sharma, N.S. Saxena, T.P. Sharma, AIP Conf. Proc. 1004 (2008) 311.

[25] K. Menard, Dynamic Mechanical Analysis-a practical introduction, CRC press LLC, Boca raton, 1999 Chapter $4 \& 5,61-64 \& 94-100$.

[26] W.D.J. Callister, Materials Science and Engineering: an Introduction, in Characteristics, Applications and Processing of Polymers, John Wiley \& Sons, 2000.

[27] C.D. Martins, Y.M. Almeida, G.C. Nascimento, W.M. Azevedo, J. Mater. Sci. 41 (2006) 7413.

[28] S. Latitha, R. Sathyamoorthy, S. Senthilarasu, A. Subbarayan, K. Natarajan, Sol. Energy Mater. Sol Cells 82 (2004) 187.

[29] C. Manoharan, R. Venkatachalapathy, S. Dhanapandian, K. Deenadayalan, Ind. J. Pure Appl. Phys. 45 (2007) 860.

[30] M. Ohman, D. Persson, C. Leygraf, Prog. Org. Coat. 57 (2006) 78. 